\title{
Cognitive impairment is correlated with reduced quality of life in patients with clinically isolated syndrome
}

\author{
Comprometimento cognitivo correlaciona-se com redução da qualidade de vida em \\ pacientes com síndrome clinicamente isolada
}

Carolina Fiorin Anhoque1, Laurentino Biccas-Neto², Simone Cristina A. Domingues³, Antônio Lúcio Teixeira Renan Barros Domingues 5

\begin{abstract}
Objective: To evaluate the quality of life (QoL) and potential QoL determinants in patients with clinically isolated syndrome (CIS). Methods: Eighteen CIS patients and eighteen controls were submitted to QoL evaluation with Functional Assessment of Multiple Sclerosis QoL instrument (FAMS). Cognition was evaluated with specific battery tests; Anxiety and depression with Beck Anxiety (BAI) and Depression (BDI) Inventories and Neurological disability with Guy's Neurological Disability Scale (GNDS). Results: There was a significant difference in QoL between CIS patients and controls. CIS patients had worse performance in Paced Auditory Serial Addition 2 seconds ( $p=0.009)$ and fluency tests $(p=0.0038)$. There was a significant difference in BAI $(p=0.003)$, but no significant difference in BDI between patients and controls. There were significant correlations between QoL measure and verbal fluency and Stroop's test. Conclusions: Cognition, but not anxiety, depression and disability, was associated with reduced quality of life.
\end{abstract}

Key words: clinically isolated syndrome, quality of life, cognition, depression, anxiety.

RESUMO

Objetivo: Avaliar a qualidade de vida (QoL) e seus potenciais determinantes em pacientes com síndrome clinicamente isolada (SCI). Métodos: Dezoito pacientes com SCl e 18 controles realizaram avaliação da QoL com Escala de Determinação da QoL na Esclerose Múltipla; cognição foi avaliada com bateria de testes específica; ansiedade e depressão com os Inventários de Beck de ansiedade (BAI) e de depressão (BDI) e a incapacidade neurológica com a Guy's Neurological Disability Scale. Resultados: Houve diferença significativa na QoL avaliada entre pacientes com SCl e controles. Pacientes com SCl apresentaram pior desempenho no Pased Auditory Serial Addition 2 segundos ( $p=0,009)$ e na fluência verbal $(p=0,0038)$. Houve diferença no BAI $(p=0,003)$, entretanto sem diferença do BDI entre pacientes e controles. Houve correlações significativas entre QoL, fluência verbal e Stroop. Conclusões: Alterações cognitivas tiveram correlação com diminuição da QoL, o que não ocorreu com a depressão, ansiedade e incapacidade neurológica.

Palavras-Chave: síndrome clinicamente isolada, qualidade de vida, cognição, depressão, ansiedade.

Clinically isolated syndrome (CIS) is defined as the first episode of a demyelinating and inflammatory disease of the central nervous system (CNS), and most patients with CIS will convert to multiple sclerosis (MS) ${ }^{1,2}$. The most common CIS manifestations are optic neuritis, myelitis, brainstem, and/or cerebellar syndromes ${ }^{2}$. Patients with the first clinical episode of demyelination may already be diagnosed as having MS if both gadolinium-enhancing and non-enhancing lesions on the baseline magnetic resonance imaging (MRI) are found ${ }^{3}$.

\footnotetext{
'Speech Therapy, Neuroscience Post-graduation Program, Federal University of Minas Gerais, Belo Horizonte MG, Brazil;

${ }^{2}$ M.D., Ph.D., Ophthalmology Professor, Surgery Department, Santa Casa School of Health Sciences, Vitória ES, Brazil;

${ }^{3}$ Ph.D., Neuropsychologist, Vitória ES, Brazil;

${ }^{4}$ M.D., Ph.D., Professor of Neurology, Neuropsychiatric Branch, Neurology Unit, University Hospital and Neuroscience Post-graduation Program, Federal University of Minas Gerais, Belo Horizonte MG, Brazil;

${ }^{5}$ M.D., Ph.D., Professor, Department of Pathology and Internal Medicine, Santa Casa School of Health Sciences, Vitória ES, Brazil, and Neuroscience Postgraduation Program, Federal University of Minas Gerais, Belo Horizonte MG, Brazil.

Correspondence: Renan Barros Domingues; Rua Prof. Almeida Cousin 125, sala 1310, Bairro Enseada do Suá; $29055-565$ Vitória ES - Brasil;

E-mail:contato@renandomingues.med.br

Conflict of interest: There is no conflict of interest to declare.
}

Support: Antonio Lucio Teixeira receives a CNPq scholarship.

Received 03 September 2012; Received in final form 27 September 2012; Accepted 04 October 2012 
Some recent studies have shown that CIS patients may present mild cognitive impairment, especially in processing speed and executive functions ${ }^{4-6}$. Depression and anxiety have also been found in patients with CIS but their precise prevalence in this population is still unknown $n^{6-9}$. Quality of life has been studied in patients with multiple sclerosis (MS) but there are no previous studies evaluating quality of life in patients with CIS.

Several studies have showed that cognitive dysfunction, anxiety, and depression impact significantly on the quality of life of MS patients ${ }^{10-12}$. Considering that CIS is associated with cognitive dysfunction, depression and anxiety, it is possible that it can affect quality of life in patients with CIS. However, quality of life in patients with CIS is still poorly understood ${ }^{6,9,13-15}$. The present study aimed to evaluate the quality of life of patients with CIS and to evaluate potential determinants of quality of life such as cognition, depression and anxiety in patients with CIS.

\section{METHODS}

\section{Subjects}

Subjects aged 19-48 with CIS were recruited in the Multiple Sclerosis Clinic of Santa Casa School of Health Sciences, Vitória, Espírito Santo, Brazil. The control group was composed of healthy subjects randomly selected and paired by age, gender, and education level. The study was approved by the ethics committees of Federal University of Minas Gerais and School of Health Sciences of Santa Casa, Vitoria. Informed consent form signature was obtained from each participant. The diagnosis of CIS was done according to the following criteria: one isolated neurological episode lasting at least 24 hours compatible with demyelination of the central nervous system and magnetic resonance imaging showing at least two lesions similar to those seen in $\mathrm{MS}^{1,3}$. Patients fulfilling diagnostic criteria of dissemination in time with baseline MRI were excluded ${ }^{3}$. Patients with severe cognitive impairment defined as score bellow 24 points in the Mini-Mental State Examination ${ }^{16}$ or using psychotropic drugs were not included.

Quality of life, neurologic, neuropsychological, neuropsychiatric evaluation

All patients and control subjects completed the Functional Assessment of Multiple Sclerosis quality of life instrument $(\text { FAMS })^{17}$ which is validated in Portuguese language.

The neurologic evaluation included a complete history and determination of current disability using the Expanded Disability Status Scale (EDSS) ${ }^{18}$. Disability and activity limitations were assessed with Guy's Neurological Disability Scale $(\text { GNDS })^{19}$. Anxiety was evaluated with Beck Anxiety Inventory $(B A I)^{20,21}$. The Beck Depression Inventory (BDI) ${ }^{22}$ was used to evaluate depression.
CIS subjects and control group were submitted to neuropsychological evaluation which included: verbal learning and verbal retention (logical memory subtest from Wechsler memory scale-revised; Rey Auditory Verbal Learning Test); visual-spatial ability (Rey Complex Figure), information processing speed (Paced Auditory Serial Addition Test 3 and 2 seconds), working memory (Digit Span Test, Wechsler memory scale revised), executive functions (verbal fluency 'animals' and 'letter S' and Stroop's color test), and attention (D2 test; Digit Symbol).

\section{Data analysis}

Analyses were performed using 'R' software, version 2.8.0. The normality of data distribution was assessed with the Shapiro-Wilk test. Mann-Whitney test was used to compare the results of quality of life, cognitive tests, anxiety and depression symptoms between CIS patients and controls. The correlations between quality of life parameters and potential quality of life determinants including neurological disability, depression, anxiety, and cognition were evaluated in patients with CIS using the Spearman correlation test. Significance level was set at $\mathrm{p}<0.05$.

\section{RESULTS}

Eighteen CIS patients were included, 13 female. The clinical and demographical data of CIS as well as the mean \pm SD EDSS score of patients with CIS was $0.8 \pm 0.5$ patients are shown in Table 1 . Table 2 shows the comparison of quality of life, disability, depression and anxiety between patients and controls. The cognitive evaluation showed significant differences between patients and controls in the following tests: PASAT $2(\mathrm{p}=0.0216)$ and verbal fluency with letters $(\mathrm{p}=0.0038)$. No differences between CIS and controls were found in the other neuropsychological tests.

In patients with CIS, there are correlations between quality of life evaluated by FAMS with cognitive tests (verbal fluency with letters and stroop card test) (Table 3). FAMS is not correlated with neurological disability, activity limitations, depression and anxiety (Table 3).

\section{DISCUSSION}

Our study demonstrated reduction in the quality of life of patients with CIS. Reduced quality of life was previously demonstrated in patients with $\mathrm{MS}^{23}$. Considering that CIS may be the first manifestation of MS and that the neuropathological abnormalities are the same only differing in intensity and distribution it seems reasonable that CIS may affect quality of life. It is possible that the impact of MS on quality of life is higher than in CIS since MS patients usually have higher 
Table 1. Demographic and clinical data of CIS patients and controls.

\begin{tabular}{|c|c|c|c|}
\hline & \multicolumn{2}{|c|}{ "n" and Mean ( \pm SD) } & \multirow{2}{*}{$\mathrm{p}$-value } \\
\hline & Controls & Patients & \\
\hline Age & $18 ; 35.5(9.2)$ & $18 ; 35.6(9.3)$ & 0.9747 \\
\hline Females & 13 & 13 & - \\
\hline Males & 5 & 5 & - \\
\hline EDSS & - & $18 ; 0.8(0.5)$ & - \\
\hline $\begin{array}{l}\text { Time between symptom and } \\
\text { first assessment (years) }\end{array}$ & - & $\begin{array}{l}18 ; 2.09 \\
(2.6)\end{array}$ & - \\
\hline Education (years) & $\begin{array}{c}18 ; 14.2 \\
(4.2)\end{array}$ & $\begin{array}{c}18 ; 14.1 \\
(4.3)\end{array}$ & 0.9747 \\
\hline \multicolumn{4}{|l|}{ CIS symptom localization } \\
\hline Lobar & - & 2 & - \\
\hline Brainstem & - & 1 & - \\
\hline Spinal Cord & - & 5 & - \\
\hline Optic neuritis & - & 10 & - \\
\hline
\end{tabular}

SD: standard deviation; CIS: clinically isolated syndrome; EDSS: Expanded Disability Status Scale.

neurological disability and higher rates of depression and anxiety'; however, future studies are still needed to compare the reduction in quality of life in CIS and in MS patients.

Previous studies showed that CIS patients may have impairment in memory, information processing speed, attention, semantic verbal memory, and working memory. Our findings are in line with previous studies showing neuropsychological impairment in patients with CIS ${ }^{4-6,24}$. All previous studies of cognition in CIS as well as the present study showed changes in executive function evaluation, such as speed of information processing and verbal fluency,5,624-26.

There was no significant difference between BDI score of patients and controls in the present study. Previous studies have reported depression in patients with $\mathrm{CIS}^{8,11}$. Di Legge et al. ${ }^{27}$ reported depression in CIS patients with a tendency towards normalization after a relapse free period. A correlation between temporal lobe lesion load and depressive scores was previously found ${ }^{27}$. A possible explanation for the lack of significant reduction of CIS BDI scores compared to controls in the present study might be the low number of CIS patients not allowing a statistically significant difference to be demonstrated. Also, it was not possible to evaluate the MRI lesion sites and lesion load, and therefore it is not possible to rule out that the distribution of the lesions in this group of patients has not favored the emergence of depressive symptoms. It is also not possible to rule out that the low mean EDSS score of the CIS group explain the low depressive scores. In fact, previous studies presented a tendency to correlation between depression and disability?

There were higher anxiety scores in CIS patients when compared with control group. Few studies explored anxiety in CIS patients. It was shown that the severity of anxiety symptoms are related with the EDSS score and time of disease, suggesting that anxiety worsens as the disease progresses $^{28}$. Psychological aspects have been suggested to be
Table 2. GNDS and FAMS scale results and depression and anxiety scores of CIS patients and controls.

\begin{tabular}{|c|c|c|c|}
\hline & \multicolumn{2}{|c|}{ Median } & \multirow{2}{*}{$p$-value } \\
\hline & Controls & Patients & \\
\hline FAMS (total score) & 168 & 149 & $0.000 *$ \\
\hline GNDS (total score) & 0 & 2 & $0.000 *$ \\
\hline Depression symptoms (score BDI) & 5.0 & 6.5 & 0.198 \\
\hline Anxiety symptoms (score BAI) & 5.5 & 11.0 & $0.003^{*}$ \\
\hline
\end{tabular}

*Significant; GNDS: Guy's Neurological Disability Scale; FAMS: Functional Assessment of Multiple Sclerosis QoL instrument; CIS: clinically isolated syndrome; BDI: beck depression inventory; BAI: beck anxiety inventory.

Table 3. Correlation between quality of life (FAMS) with neurological disability (EDSS), activity limitations (GNDS), cognition, depression (BDI) and anxiety (BAI) correlations.

\begin{tabular}{lc} 
& FAMS \\
\cline { 2 - 2 } & p-value \\
\hline EDSS & 0.159 \\
GNDS & 0.444 \\
BDI & 0.324 \\
BAI & 0.451 \\
COGNITION & \\
PASAT 3 Seconds (Correct responses) & 0.102 \\
PASAT 2 Seconds (Correct responses) & 0.214 \\
Fluency (Letter) & $0.014^{\star}$ \\
Fluency (Animals) & 0.153 \\
Stroop (Time) (Card3) & $0.020 *$ \\
RALVT (Total) & 0.272 \\
Digit Symbol (Score) & 0.414 \\
Digit Span (Total) & 0.050 \\
D2 (Gross) & 0.055 \\
\hline
\end{tabular}

*Significant; FAMS: Functional Assessment of Multiple Sclerosis QoL instrument EDSS: Expanded Disability Status Scale; GNDS: Guy's Neurological Disability Scale; BDI: beck depression inventory; BAI: beck anxiety inventory; PASAT: Paced Auditory Serial Addition; RALVT: Rey auditory Verbal Learning.

determinants of anxiety symptoms in patients with demyelinating disease ${ }^{29}$, but there is no conclusive explanation for the causes of anxiety in CIS.

No previous studies explored quality of life determinants in CIS. In the present study we sought if neurological disability, activity limitations, cognition, depressive symptoms and anxiety had correlation with quality of life scores. Significant correlations were found between FAMS and verbal fluency with letters and Stroop's card test. Quality of life was not correlated with depression, anxiety, neurological disability and activity limitations. It has been previously shown that cognitive impairment affects quality of life in $\mathrm{MS}^{12}$ but this is the first report showing that this occurs in CIS.

Our study has some limitations. The sample size may be considered small not allowing a definitive conclusions about the determinants of quality of life. Also, the diagnoses of anxiety and depression were not based on a strict and formal psychiatric evaluation. However, Beck inventories for anxiety 
and depression have been used in all patients. These instruments are largely used, both in clinical practice and research.

It was not possible to correlate quality of life, cognition and neuropsychiatric findings with MRI evaluation and current treatment.
In conclusion, this study found reduced quality of life in patients with CIS. Our study suggests that cognitive impairment may be a more important determinant of impaired quality of life in CIS than neurological disability, depressive symptoms and anxiety.

\section{References}

1. Tintoré M, Rovira A, Rio J, et al. Is optic neuritis more benign than other first attacks in multiple sclerosis? Ann Neurol 2005;57:210-215.

2. Thrower BW. Clinically isolated syndromes: predicting and delaying multiple sclerosis. Neurology 2007;68(Suppl 4):S12-S15.

3. Polman $\mathrm{CH}$, Reingeold SC, Banwell B, et al. Diagnostic Criteria for Multiple Sclerosis: 2010 Revisions to the McDonald Criteria. Ann Neurol 2011;69:292-302

4. Feuillet L, Reuter F, Audoin B, et al. Early cognitive impairment in patients with clinically isolated syndrome suggestive of multiple sclerosis. Mult Scler 2007;13:124-127.

5. Potagas C, Giogkaraki E, Koutsis G, et al. Cognitive impairment in different MS subtypes and clinically isolated syndromes. J Neurol Sci 2008;267:100-106.

6. Anhoque CF, Domingues SCA, Teixeira AL, Domingues RB. Cognitive impairment in clinically isolated syndrome: a systematic review. Dement Neuropsychol 2010;4:86-90.

7. Chwastiak L, Ehde DM, Gibbonns LE, Sullivan M, Bowen JD, Kraft GH. Depressive symptoms and severity of illness in multiple sclerosis: epidemiologic study of a large community sample. Am J Psychiatry 2002;159:1862-1868.

8. Beiskea AG, Svenssonb EC, Sandangerd I, et al. Depression and anxiety amongst multiple sclerosis patients. Eur J Neurol 2008;15:239-245.

9. Anhoque CF, Domingues SCA, Carvalho T, Teixeira AL, Domingues RB. Anxiety and depressive symptoms in clinically isolated syndrome and multiple sclerosis. Arq Neuropsiquiatr 2011;69:882-886

10. Wang JL, Reimer MA, Metz LM, Patten SB. Major depression and quality of life in individuals with multiple sclerosis. Int J Psychiatry Med 2000;30:309-317.

11. Janssens ACJW, Van Doorn PA, De Boer JB, et al. Anxiety and depression influence the relation between disability status and quality of life in multiple sclerosis. Mult Scler 2003;9:397-403.

12. Benedict RHB, Carone DA, Bakshi R. Correlating brain atrophy with cognitive dysfunction, mood disturbances, and personality disorder in multiple sclerosis. J Neuroimaging 2004;14:36-45.

13. Feinstein A, Kartsounis LD, Miller DH, Youl BD, Ron MA. Clinically isolate lesions of the type seen in multiple sclerosis: a cognitive, psychiatric and MRI follow-up study. J Neurol Neurosurg Psychiatry 1992;55:869-876.

14. Mohr DC, Goodkin DE, Gatto N, Wende V. Depression, coping and level of neurological impairment in multiple sclerosis. Mult Scler 1997;3:254-258

15. Simioni S, Ruffieux C, Bruggimann L, Annoni JM, Schluep M. Cognition, mood and fatigue in patients in the early stage of multiple sclerosis. Swiss Med Wkly 2007;137:496-501.
16. Folstein MF, Folstein SE, McHugh PR. Mini-mental state: a practical method for grading the cognitive state of patients for the clinician. J Psychiatric Res 1975;12:189-198.

17. Mendes, MF, Balsimelli S, Stangehaus G, Tilbery CP. Validação de escala de determinação funcional da qualidade de vida na esclerose múltipla para a língua portuguesa. Arq Neuropsiquiatr 2004;62: 108-113.

18. Kurtzek JF. Rating neurologic impairment in multiple sclerosis: an expanded disability status scale (EDSS). Neurology 1983;33: 1444-1452.

19. Araujo CR, Simão LM, Ybarra Ml, et al. Validation of the Brazilian version of Guy's Neurological Disability Scale. Arq Neuropsiquiatr 2007;65:615-618

20. Beck, AT, Brown, G, Epstein, N, Steer, RA. An inventory for measuring clinical anxiety: psychometric properties. J Consul Clin Psychol 1988;56:893-897.

21. Gorestein, C, Andrade, L. Inventário de Depressão de Beck: propriedades psicométricas da versão em português. Rev Psiq Clín 1998;25:245-250.

22. Beck AT, Ward CH, Mendelson M, Morck J, Erbaugh J. An inventory for measuring depression. Arch Gen Psych 1961;4:53-63.

23. Rao SM, Leo GJ, Ellington L, Nauertz T, Bernardin L, Unverzagt F. Cognitive dysfunction in multiple sclerosis II. Impact on employment and social functioning. Neurology 1991;41:692-696.

24. Amato MP, Zipoli V, Goretti B, et al. Benign multiple sclerosis cognitive, psychological and social aspects in a clinical cohort. J Neurol 2006:253:1054-1059.

25. Nilsson P, Rorsman I, Larsson EM, Norrving B, Sandberg-Wollheim M Cognitive dysfunction 24-31 years after isolated optic neuritis. Mult Scler 2008;14:913-918.

26. Summers M, Swanton J, Fernando K, et al. Cognitive impairment in multiple sclerosis can be predicted by imaging early in the disease. $J$ Neurol Neurosurg Psychiatry 2008;79:955-958.

27. Di Legge S, Piatella MC, Pozzilli C, et al. Longitudinal evaluation of depression and anxiety in patients with clinically isolated syndrome at high risk of developing early multiple sclerosis. Mult Scler 2003:9:302-306.

28. Siepman TAM, Janssens ACJW, Koning I, Polman $\mathrm{CH}$, Boringa $J B$, Hintzen RQ. The role of disability and depression in cognitive functioning within 2 years after multiple sclerosis diagnosis. J Neurol 2008;255:910-916

29. Sá MJ. Psychological aspects of multiple sclerosis. Clin Neurol Neurosurg 2008;110:868-877. 